\title{
Some Aspects of Multiparticle Production in Relativistic Nuclear Collisions
}

\author{
M. I. Haque1, M. Tariq², Hushnud Jahan², Tahir Hussain ${ }^{3}$ \\ ${ }^{1}$ Department of Kulliyat, AK Tibbiya College, AMU, Aligarh, India \\ ${ }^{2}$ Department of Physics, AMU, Aligarh, India \\ ${ }^{3}$ Department of Applied Physics, AMU, Aligarh, India

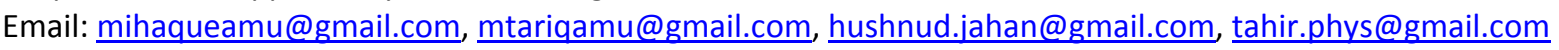

Received 3 March 2014; revised 1 April 2014; accepted 26 April 2014

Copyright (C) 2014 by authors and Scientific Research Publishing Inc.

This work is licensed under the Creative Commons Attribution International License (CC BY).

http://creativecommons.org/licenses/by/4.0/

cC) (7) Open Access

\section{Abstract}

An attempt is made to study various types of multiplicity distributions and multiplicity correlations amongst secondary charged particles produced in 4.5 and $14.5 \mathrm{~A} \mathrm{GeV} / \mathrm{c}^{28} \mathrm{Si}$-nucleus interactions. The results reveal that multiplicity correlations of the type $n_{i}-\left\langle n_{j}\right\rangle$, where $i, j=b, g, s$ and $h$ with $\mathbf{i} \neq \mathbf{j}$, are linear. The observed multiplicity correlations are nicely fitted by the method of least squares fitting of the type, $\left\langle\mathbf{n}_{j}\right\rangle=b+a n_{i}$. Furthermore, the multiplicity distributions of relativistic charged particles and compound multiplicity at $4.5 \mathrm{~A} \mathrm{GeV} / \mathrm{c}$ are nicely fitted by Poisson distributions with peaks at relatively lower multiplicities. However, in the case of multiplicity distributions of various types of secondary charged particles produced in $14.5 \mathrm{~A} \mathrm{GeV} / \mathrm{c}^{28} \mathrm{Si}$-nucleus collisions definite trends are not discernible.

\section{Keywords}

Line Scanning, Multiplicity, Correlations, Negative Binomial Distribution

\section{Introduction}

Study of high energy nucleus-nucleus collisions has been attracting the attention of high energy physicists during the last decades due to the possibility of production of nuclear matter under extreme conditions of temperature and energy density [1]. In order to understand the behaviour of the nuclear matter produced in high energy nuclear collisions, one investigates the dynamics of multiparticle production in these collisions. Certain aspects of relativistic nuclear interactions, such as multiplicity distributions, multiplicity correlations and pseudorapidity distributions are expected to provide invaluable information regarding formation of quark-gluon plasma in rela- 
tivistic nucleus-nucleus collisions.

Generally, efforts are made to study general characteristics of various types of secondary charged particles produced in high energy nuclear collisions, which may reveal some interesting and useful information regarding multiparticle production processes involved in such collisions. In particular, study of correlations amongst $\left\langle\mathrm{n}_{\mathrm{g}}\right\rangle$, $\left\langle\mathrm{n}_{\mathrm{b}}\right\rangle,\left\langle\mathrm{n}_{\mathrm{h}}\right\rangle$, and $\left\langle\mathrm{n}_{\mathrm{c}}\right\rangle$ and $\mathrm{n}_{\mathrm{s}}$ may provide useful information which may help understand the mechanism of multiparticle production in high energy nuclear interactions.

Keeping in view these objectives, an attempt is made to study correlations between the mean multiplicities of grey, black, heavily ionizing charged particles, $\left\langle\mathrm{n}_{\mathrm{g}}\right\rangle,\left\langle\mathrm{n}_{\mathrm{b}}\right\rangle,\left\langle\mathrm{n}_{\mathrm{h}}\right\rangle$ and mean compound multiplicity, $\left\langle\mathrm{n}_{\mathrm{c}}\right\rangle$ and $n_{s}$ produced in the collisions of 4.5 and $14.5 \mathrm{~A} \mathrm{GeV} / \mathrm{c}^{28} \mathrm{Si}$ nuclei with nuclear emulsion. Some other observables of the charged particles produced in these collisions have also been determined. For comparing our experimental results with the corresponding theoretically predicted values, a matching number of events were generated by the Lund model, FRITIOF.

\section{Experimental Details}

Present analysis is carried out using the data obtained by exposing two emulsion stacks to the beams of Silicon nuclei of energies 4.5 and 14.5 A GeV/c from AGS (Alternating Gradient Synchrotron), Brookhaven National Laboratory, USA. The interactions were recorded by line scanning procedure; NIKON (LABOPHOT and Tc-

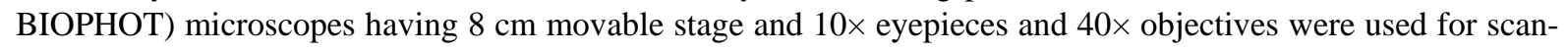
ning the pellicles. However, for measuring ionization of the tracks, $100 \times$ objectives and $15 \times$ eyepieces were used. In the line scanning method, each primary track is followed in a systematic manner until it causes an interaction or leaves the pellicle. Following criteria were employed for selecting the interactions:

1. The incident beam should not be inclined more than $3^{\circ}$ with respect to the mean beam direction and

2. Only those events, which lie at a depth $\geq 20 \mu \mathrm{m}$ from the top or the bottom surface of the emulsion pellicle, have been considered.

To investigate the characteristics of secondary charged particles, two random samples comprising 500 and 430 interactions having $n_{h} \geq 0$ produced in 4.5 and $14.5 \mathrm{~A} \mathrm{GeV/c}{ }^{28}$ Si-emulsion collisions, where $n_{h}$ represents the number of charged particles produced in an interaction with relative velocities, $\beta \leq 0.7$, are considered. The secondary charged particles produced in these collisions are separated into shower, grey, black and heavily ionizing particles on the basis of their specific ionizations or velocities [2] [3]. The tracks produced by the secondary charged particles having relative velocities $\beta \geq 0.7$ are referred to as shower tracks and those having velocities in the range $0.3 \leq \beta \leq 0.7$ are called grey tracks and the rest with relative velocities $\beta<0.3$ are known as black tracks; grey and black tracks are jointly referred to as heavy tracks or heavily ionizing tracks. The numbers of shower (s), grey (g), black (b) and heavily ionizing (h) tracks produced in an interaction are represented by $\mathrm{n}_{\mathrm{s}}$, $\mathrm{n}_{\mathrm{g}}, \mathrm{n}_{\mathrm{b}}$ and $\mathrm{n}_{\mathrm{h}}$ respectively.

\subsection{Shower Tracks}

These tracks are mostly produced by relativistic charged pions. The number of such tracks emitted from an interaction is denoted by $n_{s}$.

\subsection{Grey Tracks}

Grey tracks are produced mostly by recoil protons, which carry vital information about intra-nuclear cascading; small numbers of deuterons and tritons may also produce grey tracks. The number of grey tracks in an interaction is represented by $n_{\mathrm{g}}$.

\subsection{Black Tracks}

Target associated secondary particles form black tracks, mostly emitted due to de-excitation of the excited target nuclei through evaporation. The specific ionization, $\mathrm{g}^{*}$, of these particles are greater than 10 . These are mostly protons but may contain small percentage of multiply charged fragments. The number of black tracks in a collision is represented by $\mathrm{n}_{\mathrm{b}}$. The total number of charged particles produced in an interaction is denoted by $\mathrm{n}_{\mathrm{ch}}\left(=\mathrm{n}_{\mathrm{g}}\right.$ $+n_{b}+n_{s}=n_{s}+n_{h}$ ); black and grey tracks in an interaction are jointly referred to as heavily ionizing tracks, that is, $n_{h}=n_{g}+n_{b}$. The compound multiplicity, $n_{c}$, is the sum of the numbers of shower particles, $n_{s}$, and grey par- 
ticles, $\mathrm{n}_{\mathrm{g}}$, i.e., $\mathrm{n}_{\mathrm{c}}\left(=\mathrm{n}_{\mathrm{s}}+\mathrm{n}_{\mathrm{g}}\right)$.

\section{Results and Discussion}

\subsection{Mean Multiplicity}

Mean multiplicities of various types of charged particles are determined by averaging the multiplicities of various events over the total number of events considered for carrying out the analysis. Listed in Table 1 are the mean multiplicities of the secondary charged particles producing shower, grey and black tracks in the interactions of 4.5 and $14.5 \mathrm{~A} \mathrm{GeV/c}$ Silicon nuclei with emulsion.

The mean multiplicity of relativistic charged particles, $\left\langle\mathrm{n}_{\mathrm{s}}\right\rangle$, is found to increase appreciably with projectile mass. This trend, incidentally, is in good accord with the prediction of the superposition models [4] [5].

From Table 1 it is seen that the value of mean multiplicity of relativistic charged particles, $\left\langle\mathrm{n}_{\mathrm{s}}\right\rangle$, increases with increasing projectile energy. The mean multiplicity of grey particles, $\left\langle\mathrm{n}_{\mathrm{g}}\right\rangle$, also shows an increasing trend with increasing mass as well as energy of the projectile. However, the mean multiplicity of black tracks, $\left\langle\mathrm{n}_{\mathrm{b}}\right\rangle$, does not exhibit any particular trend. On the other hand, the value of the mean multiplicity of all the charged particles, $\left\langle\mathrm{n}_{\mathrm{ch}}\right\rangle$, is observed to increase with projectile energy and target mass; corresponding results for the FRITIOF generated data are also presented in the same table.

\subsection{Multiplicity Distribution}

Shown in Figures 1-4 are the distributions of multiplicities of the various kinds of secondary charged particles produced in the interactions considered in the present study. Distributions are plotted for the experimental and simulated data as indicated in the figures. The $n_{s}$ and $n_{c}$ distributions at $4.5 \mathrm{~A} \mathrm{GeV} / \mathrm{c}$ are reproduced nicely by Negative Binomial Distribution (NBD) [6]-[8] and exhibit peaks at relatively lower multiplicities. Similar trends have also been reported for h-h, h-A and A-A collisions by other workers [2]-[5]. Figure 1 represents the NBD fitted to the multiplicity distribution of shower particles and the compound multiplicity distribution for the data on $4.5 \mathrm{GeV} / \mathrm{C}^{28} \mathrm{Si}$-nucleus collisions. It is worth mentioning that the two distributions are reproduced reasonably well by NBD having the following form:

$$
\mathrm{p}(\mathrm{n}, \overline{\mathrm{n}}, \mathrm{k})=\frac{\mathrm{k}(\mathrm{k}+1) \cdots(\mathrm{k}+\mathrm{n}-1)}{\mathrm{n} !}\left(\frac{\frac{\overline{\mathrm{n}}}{\overline{\mathrm{k}}}}{1+\frac{\overline{\mathrm{n}}}{\mathrm{k}}}\right)^{\mathrm{n}}\left(1+\frac{\overline{\mathrm{n}}}{\mathrm{k}}\right)^{-\mathrm{k}}
$$

where $\mathrm{n}$ and $\overline{\mathrm{n}}$ denote multiplicity and mean multiplicity respectively. The value of $\mathrm{k}$ is determined using

$$
\frac{1}{\mathrm{k}}+\frac{1}{\overline{\mathrm{n}}}=\frac{\mathrm{D}^{2}(\mathrm{n})}{\overline{\mathrm{n}^{2}}}
$$

where $D^{2}(n)$ is the square of the dispersion of multiplicity distribution.

In the various distributions for the FRITIOF data, no or very little fluctuations are discernible in comparison to the ones for the experimental data.

Table 1. Mean multiplicities of various types of secondary charged particles produced in 4.5 and $14.5 \mathrm{~A} \mathrm{GeV/c}{ }^{28} \mathrm{Si}-\mathrm{emul}-$

\begin{tabular}{|c|c|c|c|c|c|}
\hline $\begin{array}{c}\text { Energy }(\mathrm{GeV} / \mathrm{c}) \\
\text { per nucleon }\end{array}$ & $\begin{array}{l}\text { Interaction } \\
\text { type }\end{array}$ & $\left\langle n_{b}\right\rangle$ & $\left\langle\mathrm{n}_{\mathrm{g}}\right\rangle$ & $\left\langle\mathrm{n}_{\mathrm{s}}\right\rangle$ & $\left\langle\mathrm{n}_{\mathrm{ch}}\right\rangle$ \\
\hline 4.5 & $\begin{array}{l}{ }^{28} \mathrm{Si}-\mathrm{CNO} \\
{ }^{28} \mathrm{Si}-\mathrm{Em} \\
{ }^{28} \mathrm{Si}-\mathrm{AgBr}\end{array}$ & $\begin{array}{c}2.93 \pm 0.07 \\
6.74 \pm 0.40 \\
13.31 \pm 0.30\end{array}$ & $\begin{array}{l}1.53 \pm 0.06 \\
8.43 \pm 0.15 \\
7.38 \pm 0.30\end{array}$ & $\begin{array}{c}7.84 \pm 0.35 \\
13.26 \pm 0.45 \\
19.58 \pm 0.76\end{array}$ & $\begin{array}{l}12.30 \pm 0.36 \\
24.85 \pm 0.62 \\
37.79 \pm 0.95\end{array}$ \\
\hline 14.5 & $\begin{array}{l}{ }^{28} \mathrm{Si}-\mathrm{CNO} \\
{ }^{28} \mathrm{Si}-\mathrm{Em} \\
{ }^{28} \mathrm{Si}-\mathrm{AgBr}\end{array}$ & $\begin{array}{c}2.38 \pm 0.11 \\
6.96 \pm 0.22 \\
10.79 \pm 0.24\end{array}$ & $\begin{array}{l}1.54 \pm 0.11 \\
4.69 \pm 0.17 \\
7.34 \pm 0.23\end{array}$ & $\begin{array}{l}15.53 \pm 0.56 \\
22.02 \pm 0.61 \\
22.60 \pm 0.90\end{array}$ & $\begin{array}{l}19.45 \pm 0.69 \\
33.67 \pm 1.35 \\
44.24 \pm 1.16\end{array}$ \\
\hline FRITIOF & $\begin{array}{c}{ }^{28} \mathrm{Si}-\mathrm{Em}(14.5) \\
{ }^{28} \mathrm{Si}-\mathrm{Em}(4.5)\end{array}$ & $\begin{array}{l}2.02 \pm 0.08 \\
2.03 \pm 0.11\end{array}$ & $\begin{array}{l}2.96 \pm 0.18 \\
2.81 \pm 0.18\end{array}$ & $\begin{array}{l}25.56 \pm 1.28 \\
10.29 \pm 0.51\end{array}$ & $\begin{array}{l}31.86 \pm 1.27 \\
18.42 \pm 0.12\end{array}$ \\
\hline
\end{tabular}
sion collisions. 

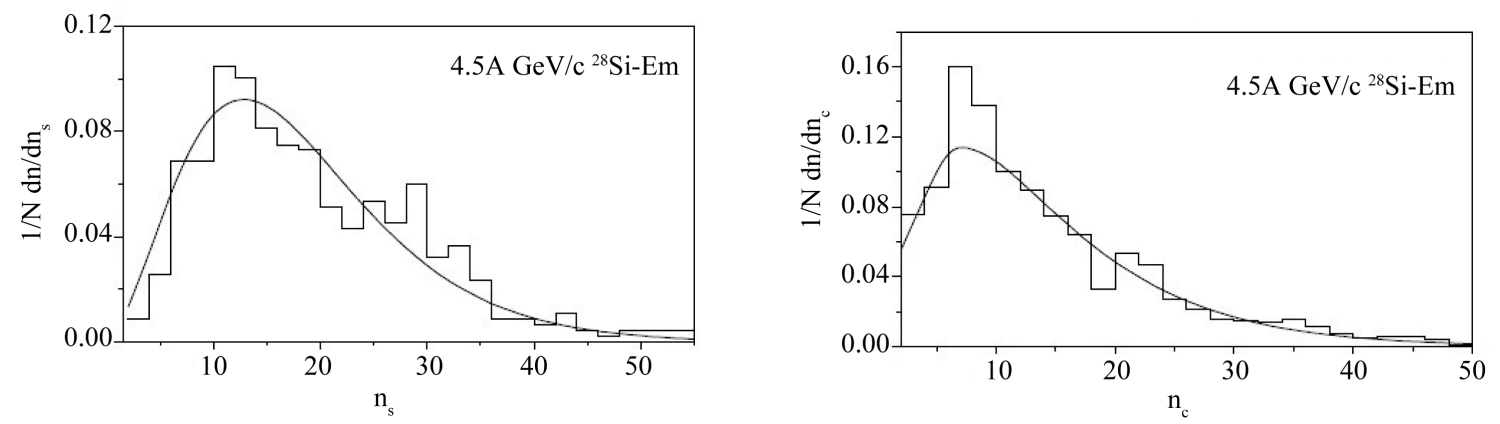

Figure 1. Multiplicity distribution of relativistic charged particles and compound multiplicity distributions with NBD fits.
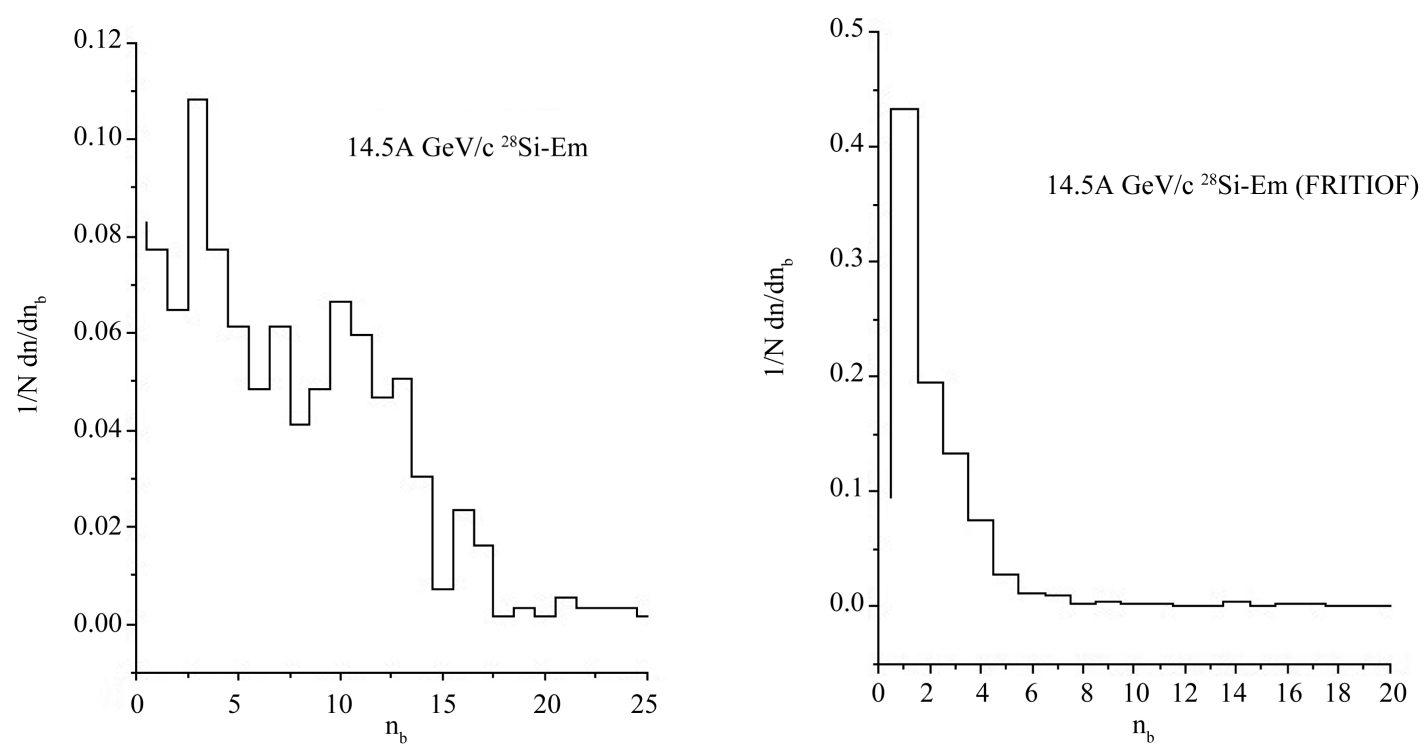

Figure 2. $\mathrm{n}_{\mathrm{b}}$ distribution.
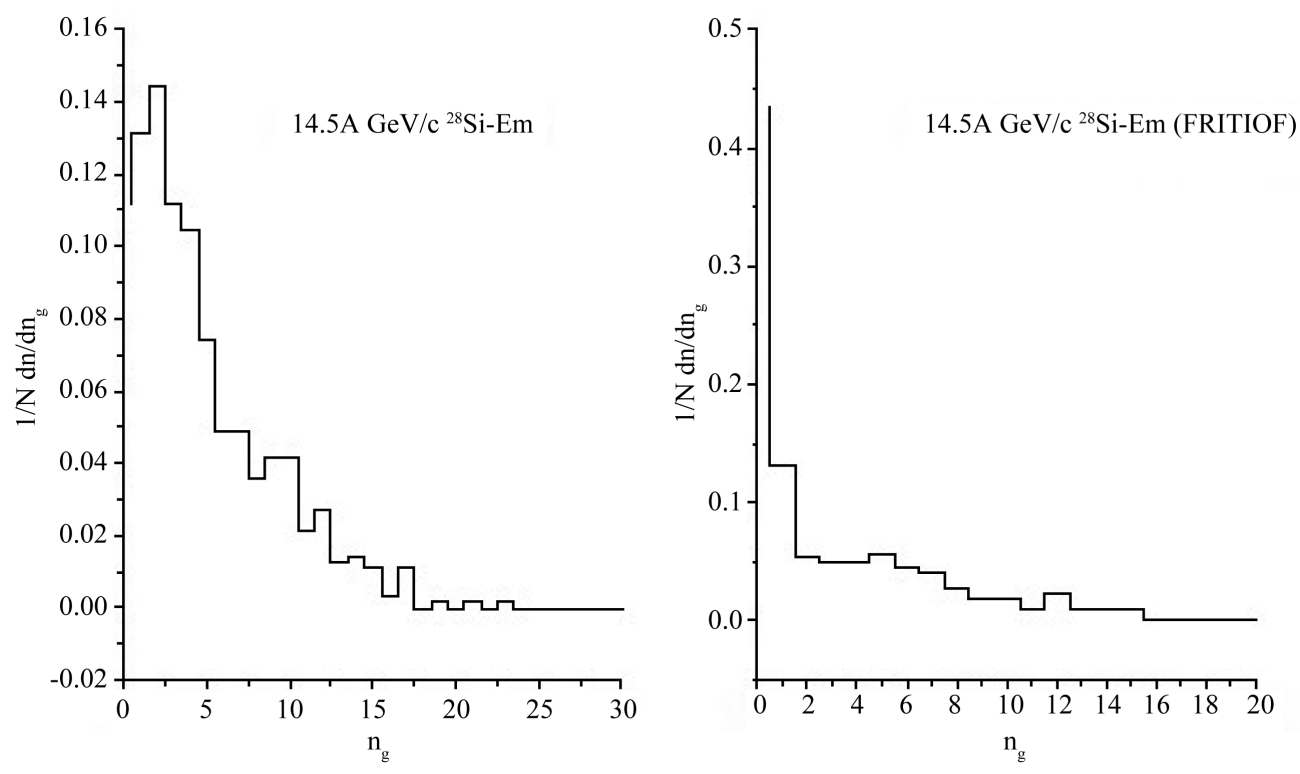

Figure 3. $n_{g}$ distribution. 

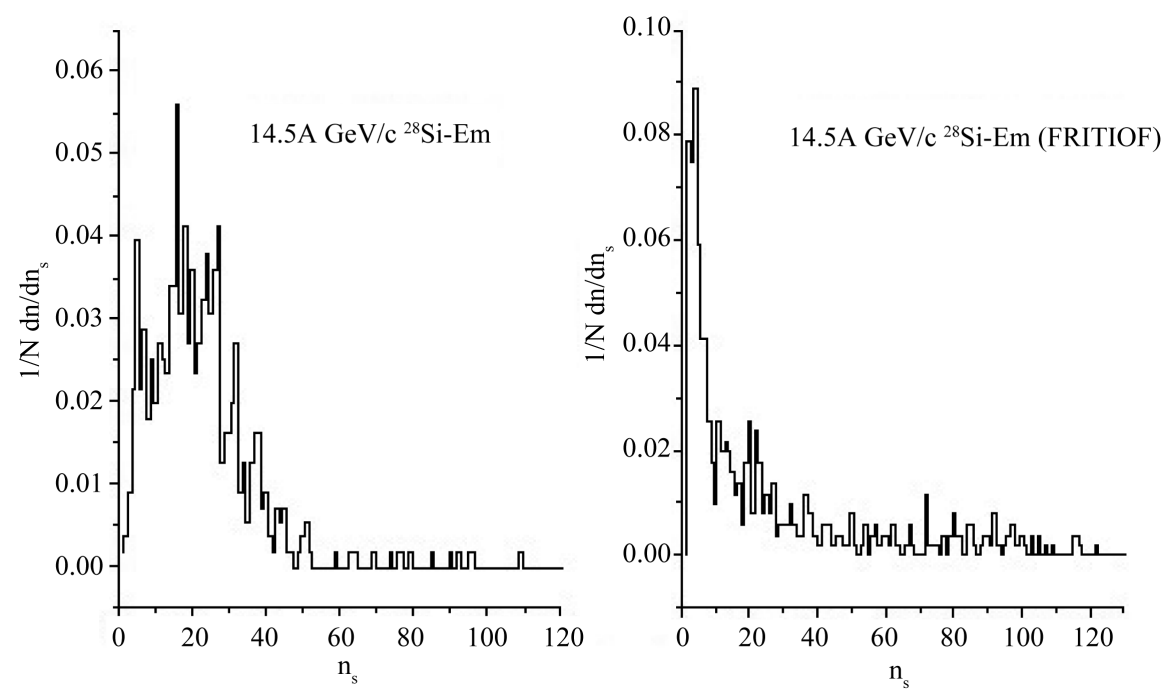

Figure 4. $\mathrm{n}_{\mathrm{s}}$ distribution.

\subsection{Multiplicity Correlations}

It is commonly believed that a study of the variations of the mean multiplicities of one kind of particles with the corresponding multiplicities of other types of particles may reveal some interesting and useful information, which may help understand the mechanism involved in the production of these particles. Several workers [5] [9] [10] have examined correlations of the type, $n_{i}-\left\langle n_{j}\right\rangle$, where $i, j=b, g, s$ and $h$ with $i \neq j$ over a wide incident energy range, involving different projectiles. Such correlations have also been investigated in the present work; these correlations are studied by carrying out least squares fittings of the type:

$$
\left\langle\mathrm{n}_{\mathrm{j}}\right\rangle=\mathrm{b}+\mathrm{an}_{\mathrm{i}}
$$

where "a" and "b" represent slope and intercept respectively.

Figure 5 shows multiplicity correlations amongst various kinds of secondary particles produced in $14.5 \mathrm{~A}$ $\mathrm{GeV} / \mathrm{C}^{28} \mathrm{Si}$-emulsion collisions. Straight lines are the best fits to the data. Strong correlations amongst different types of secondary particles are observed to occur.

Figure 5(a) shows the variation of $\left\langle n_{\mathrm{g}}\right\rangle$, with $\mathrm{n}_{\mathrm{s}}$. From the figure it is seen that the variation of $\left\langle\mathrm{n}_{\mathrm{g}}\right\rangle$ with $\mathrm{n}_{\mathrm{s}}$ is a linear one. The correlation between $\left\langle\mathrm{n}_{\mathrm{g}}\right\rangle$ and $\mathrm{n}_{\mathrm{s}}$ can also be fitted reasonably well by the following linear fit having a positive slope:

$$
\left\langle\mathrm{n}_{\mathrm{g}}\right\rangle=0.21+(0.61 \pm 0.03) \mathrm{n}_{\mathrm{s}}
$$

From Figure 5(b) it is noticed that the correlation between $\left\langle n_{b}\right\rangle$ and $n_{s}$ is nicely fitted by the following linear relationship:

$$
\left\langle\mathrm{n}_{\mathrm{b}}\right\rangle=3.56+(0.98 \pm 0.05) \mathrm{n}_{\mathrm{s}}
$$

Figure 5(c) exhibits multiplicity correlation between $\left\langle n_{h}\right\rangle$ and $n_{s}$. This too is fitted by the following linear relationship:

$$
\left\langle\mathrm{n}_{\mathrm{h}}\right\rangle=1.17+(0.44 \pm 0.03) \mathrm{n}_{\mathrm{s}}
$$

Figure 5(d) shows the variation of $\left\langle n_{c}\right\rangle$ with $n_{s}$. The variation between $\left\langle n_{c}\right\rangle$ and $n_{s}$ is nicely fitted by the following expression:

$$
\left\langle\mathrm{n}_{\mathrm{c}}\right\rangle=4.50+(0.44 \pm 0.03) \mathrm{n}_{\mathrm{s}}
$$

All these figures support existence of strong correlations amongst various types of secondary charged particles produced in $14.5 \mathrm{~A} \mathrm{GeV/c}{ }^{28} \mathrm{Si}$-emulsion collisions. 

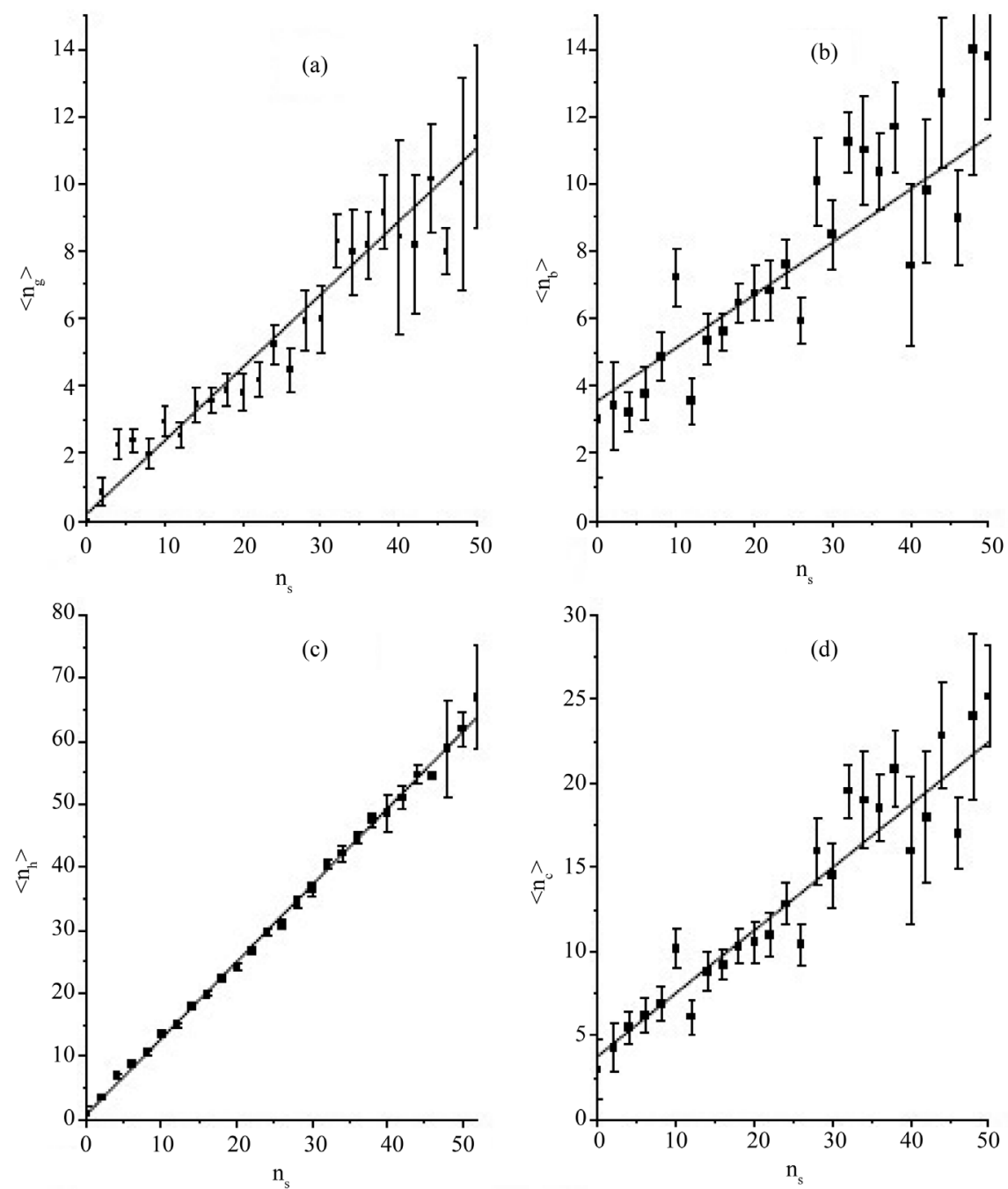

Figure 5. Variations of $<\mathrm{N}_{\mathrm{x}}>\left(\mathrm{x}=\mathrm{b}, \mathrm{g}\right.$, h and c) with $\mathrm{n}_{\mathrm{s}}$ for $14.5 \mathrm{GeV} / \mathrm{c}^{28} \mathrm{Si}-\mathrm{Em}$ interactions.

\section{Conclusions}

On the basis of the results of the present study, the following important conclusions can be arrived at:

The values of the mean multiplicities obtained in the present study are in accord with the corresponding values reported by other workers. It is interesting to mention that the multiplicity distributions of various secondary charged particles compare fairly well with those predicted by various models. The multiplicity correlations, $\left\langle\mathrm{n}_{\mathrm{g}}\right\rangle-\mathrm{n}_{\mathrm{s}},\left\langle\mathrm{n}_{\mathrm{b}}\right\rangle-\mathrm{n}_{\mathrm{s}},\left\langle\mathrm{n}_{\mathrm{h}}\right\rangle-\mathrm{n}_{\mathrm{s}}$ and $\left\langle\mathrm{n}_{\mathrm{c}}\right\rangle-\mathrm{n}_{\mathrm{s}}$, are linear ones and are represented very well by linear fits to the data. Finally, the multiplicity of relativistic charged particles is found to be linearly related to the mean multiplicity of heavily ionizing particles; all the data points are observed to lie exactly on the straight line.

\section{Acknowledgements}

We would like to express our deepest gratitude to Professor M. Irfan, Dr. Abdur Rahim Khan, Dr. Nazeer Ahmed, Dr. Mohisin Khan and Dr. Danish Azmi for their various helps during the completion of the present work. The financial support of the DST, Govt. of India is acknowledged with thanks.

\section{References}

[1] Schmidt, H.R. and Schükraft, J. (1993) Journal of Nuclear Physics, G19, 1705.

http://dx.doi.org/10.1088/0954-3899/19/11/006 
[2] Bradt, H.L. and Peters, B. (1948) Physical Review Letters, 74, 1828. http://dx.doi.org/10.1103/PhysRev.74.1828

[3] D. Ghosh, A. Deb and Swarnapratim, S. (2011) Journal of Physics G: Nuclear and Particle Physics, 38, Article ID: 065105. http://dx.doi.org/10.1088/0954-3899/38/6/065105

[4] El-Naghy, A. and Add Allah, N.N. (1994) Turkish Journal of Physics, 18, 1106.

[5] Tariq, M., Zafar, M., Tufail, A. and Ahmad, S. (1995) International Journal of Modern Physics A, E4, Article No. 2347. http://dx.doi.org/10.1142/S0218301395000109

[6] Alner, G.J., et al. (UA5 Collaboration) (1985) Physics Letters, 160B, 199.

[7] Ghosh, D., Mukhopadhyay, A., Ghosh, A. and Roy, J. (1991) Nuovo Cimento, 104A, 683.

[8] Mukhopadhyay, A., Jain, P.L. and Singh, G. (1993) Nuovo Cimento, A106, 967.

[9] Saleem Khan, M., Khushnood, H., Ansari, A.R. and Usmani, Q.N. (1995) Nuovo Cimento, A108, 147. http://dx.doi.org/10.1007/BF02816735

[10] El-Nadi, M., El-Nagdy, M.S., Shaat, E.S., Abou-Moussa, Z., Kamel, S. and Abdalla, A.M. (1997) International Journal of Modern Physics, E6, 135. http://dx.doi.org/10.1142/S0218301397000093 
Scientific Research Publishing (SCIRP) is one of the largest Open Access journal publishers. It is currently publishing more than 200 open access, online, peer-reviewed journals covering a wide range of academic disciplines. SCIRP serves the worldwide academic communities and contributes to the progress and application of science with its publication.

Other selected journals from SCIRP are listed as below. Submit your manuscript to us via either submit@scirp.org or Online Submission Portal.
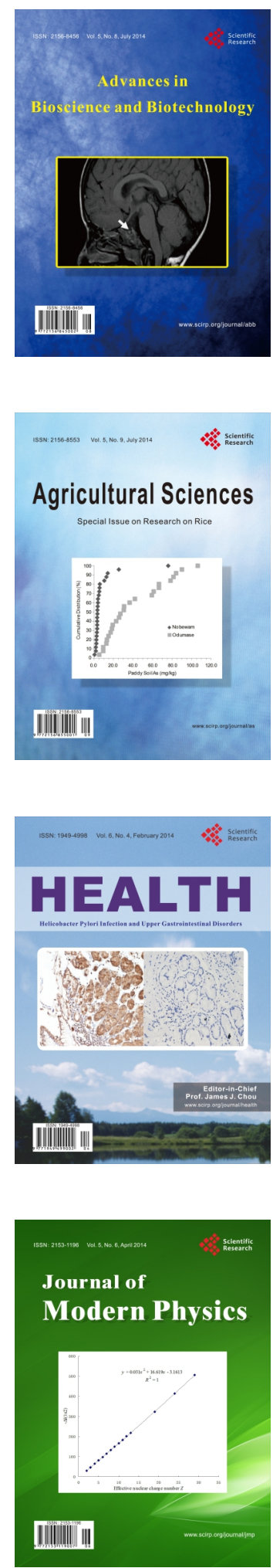
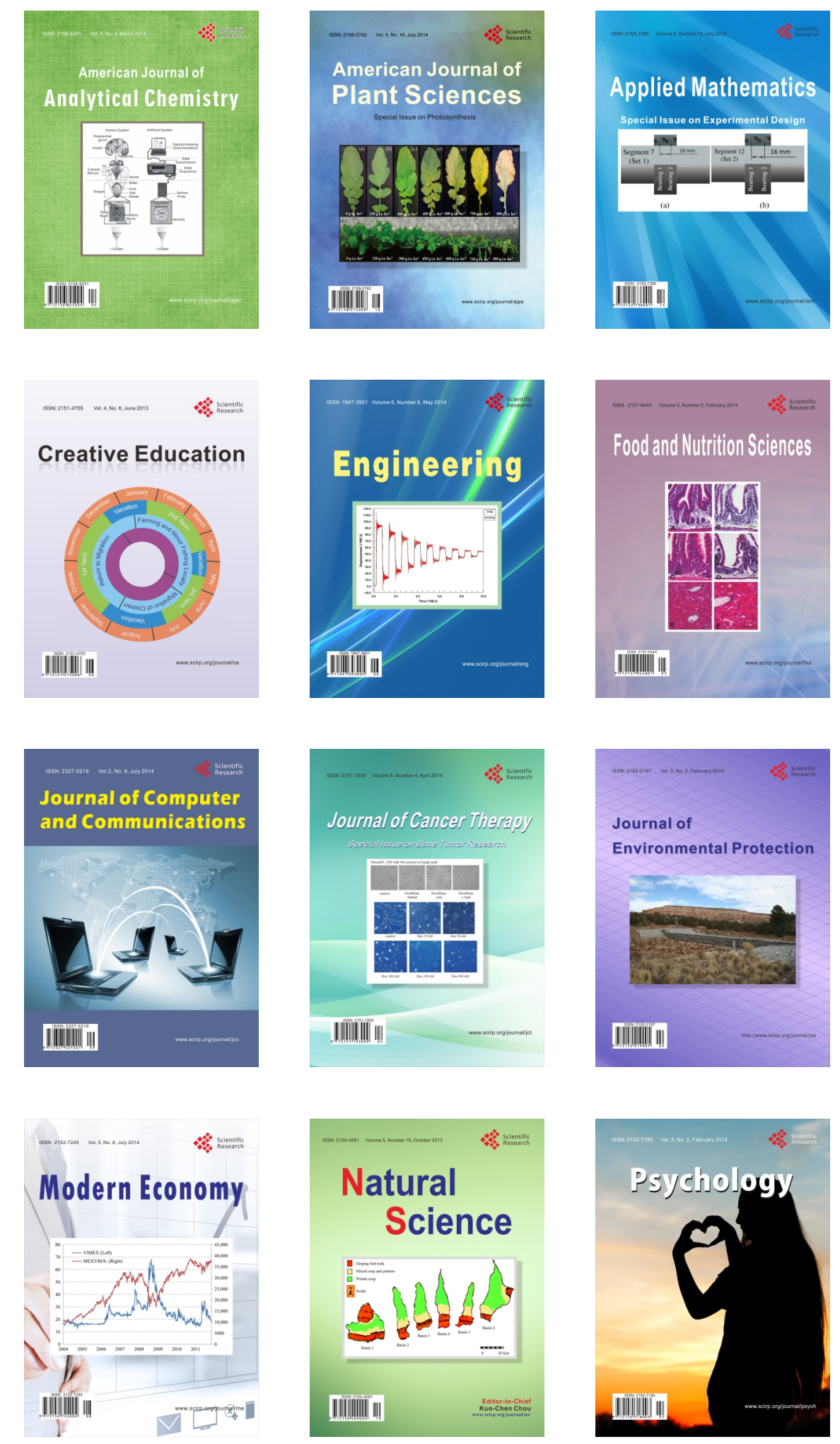